\title{
LEARNING ABOUT LEARNING ABOUT LEARNING: INSIGHTS FROM A STUDENT SURVEY IN A HYBRID CLASSROOM ENVIRONMENT
}

\author{
Guido Lang, Quinnipiac University, guido.lang@quinnipiac.edu \\ Stephen D. O'Connell, CUNY Graduate School and University Center, soconnell@gc.cuny.edu
}

\begin{abstract}
A survey among students in a hybrid undergraduate Computer Information Systems course $(N=248)$ shows that students entering college have minimal exposure to online learning and are receptive to new methods, tools, and interventions to help them navigate this evolving environment. Students with self-perceived levels of quantitative facility and self-discipline are more likely to believe they also have learning styles that are well-suited to a hybridstyle class format. Students rate time spent with material as an important potential determinant of (satisfaction with) exam performance. Moreover, students indicate that email reminders and commitment devices might be helpful to overcome informational and behavioral failures, respectively. Preferences for either type of intervention could not be predicted by typical observable characteristics of students. Ongoing research investigates the relative efficacy of these types of interventions in hybrid class formats.
\end{abstract}

Keywords: Hybrid Classroom, Informational Failures, Behavioral Failures, Email Reminders, Commitment Devices

\section{INTRODUCTION}

The move to self-direction in higher education via online and hybrid-style class formats creates a number of challenges for learners. In particular, those with little prior exposure to this type of environment may lack the specific knowledge or skills necessary to perform at desired levels. Two distinct types of failures related to individual effort may thus arise: individuals may lack sufficient information about the level of effort required to excel in such a learning environment, or the increased reliance on students' own motivation and self-direction in learning may open up the possibility for behavioral (commitment) failures even when optimal effort levels are known.

In this paper, we investigate students' perceptions the relationship between effort and performance, as well as their receptiveness towards potential interventions aimed at remedying either of the potential failures resulting in suboptimal effort described above. An ongoing debate is whether participants see value in, or specifically demand, the interventions being provided in behavioral studies. At a minimum, this relates to the specific effects being estimated, as there is a possibility that treatment effects among a population that is aware of its failure (and/or demands the treatment given through the intervention) may be different from the effects among a population that is either unaware of its failure or does not see value in the intervention being offered.

Survey results show that students are aware of the importance of time spent in online study to learning outcomes, suggesting that students are likely aware of their behavioral or informational failures. We then show that students are relatively receptive to different types of interventions that aim to address these failures. Receptiveness is not strongly related to any number of observable student characteristics, suggesting likely difficulty in predicting ex ante the types of failures different students experience. Overall, this work opens avenues for future research investigating the effectiveness of informational versus behavioral interventions in the context of hybrid classroom environments.

\section{RELATED WORK}

In recent years various modes of online instruction have captured the imaginations of university administrators anxious to cut costs. Online learning in some form will surely be an increasingly important component of university education $[3,7]$. But how do students perform in this new learning environment? Early evidence was mixed: Figlio, Rush, and Yin [5] compared students who took introductory economics online versus in a traditional lecture format 
at a major research university, while Bowen, et al. [4] examine the performance of students in an introductory statistics class held on six public university campuses, contrasting the performance of students attending a traditional class with two weekly meetings with those whose class material was delivered online supplemented by one weekly class meeting. Both studies reported no overall difference in performance as measured by test grades between formats. Participation rates in both studies were less than 25 percent, however, highlighting one difficulty of undertaking a classroom-based, semester-long randomized trial in a university setting. However, in a semester-long study with a high participation rate (96 percent) and over 700 experimental subjects, Joyce et al. [7] find that students randomly assigned to a hybrid format of introductory economics scored 3.2 out of 100 points $(0.21$ standard deviations) lower on the midterm than those in a traditional format class, although a statistically insignificant 1.6 points lower (0.11 standard deviations) on the final. The current paper seeks to begin to unpack the causes of these differences by determining the degree to which students are aware of, and demand tools to potentially remedy, their own behavioral failures in the context of hybrid learning formats.

The fact that education requires efforts in the present and gives rewards in the future gives rise to the possibility of time-inconsistent behavior - students' short-term behavior not being aligned with their long-term interests. Commitment devices [2] offer a potential solution to the problem of time-inconsistent behavior. They are a means by which people bind themselves to a pattern of behavior with penalties attached to deviations from this pattern.

Commitment devices have been found to improve short-term behavior, including the ability to perform at work [8], to save money [2,10], and to stop smoking [6]. The effectiveness of commitment devices in education has been rarely studied $[1,9]$.

Ariely and Wertenbroch [1] investigated the impact of self-imposing binding deadlines on student performance. In two sections of the same class, students were required to write and submit three papers. In one section of the class, students were given fixed, evenly-spaced deadlines to submit the papers over the course of the semester. In the other section, students were given the option to set their own deadlines. In either case, late submissions were assessed a penalty of $1 \%$ of the paper's overall grade per day. Their findings suggest that people are willing to self-impose deadlines, even when these commitments are costly (i.e. there is a penalty for missing the deadlines). However, selfimposed deadlines tend to be less effective than externally set, evenly spaced deadlines.

Patterson [9] applied commitment devices to the context of online education. In particular, he developed a commitment device that allows students to pre-commit to time limits on distracting Internet activities while completing a massively open online course (MOOC). His results indicate that students engaged in a commitment device spend more time working on the course, receive better course grades, and are more likely to complete the course.

\section{METHODS}

We use a combination of surveys and performance data that were collected over the course of the 2014-2015 academic year in twelve (12) sections of CIS 101 (Introduction to Information Systems, $N=397$ ) at a mid-sized private university in the northeastern US. CIS 101 sections have enrollment of 30-40 students each, and the course introduces students to various aspects of developing and managing computer information systems and is a required class for all freshmen in the business school. As part of CIS 101, students received three weeks of intensive Microsoft Excel training online (referred to as the Excel Boot Camp). The Excel Boot Camp content is delivered online and consists of 22 lessons, each of which consists of a short video tutorial and an exercise. Although the Excel Boot Camp is delivered online, students were still required to attend class either once or twice per week (in a standard 3-hour credit course). In each class meeting, students worked on the Excel Boot Camp (both videos and exercises) individually. Although the Excel Boot Camp is self-paced, students were required to submit their completed exercises according to a pre-defined schedule (averaging about seven exercises per week).

Two weeks after the end of the three-week Excel Boot Camp, students were tested on their knowledge of Microsoft Excel. The exam consisted of 20 multiple-choice questions, most of which require students to download an Excel worksheet and perform analyses in order to derive an answer. All exam questions were directly linked to one of the 22 lessons in the Excel Boot Camp. Given the two-week lag between the completion of the Excel Boot Camp and 
the exam, students were encouraged to go back and review lessons in the Excel Boot Camp during the exam study period.

Several weeks after the exam, the students completed a short survey $(N=248,62 \%$ response rate) that asked them a range of questions broadly relating to their learning experience in a hybrid environment. In particular, we asked about students' previous experience with online courses, whether students' felt that their learning style is well-suited to a hybrid class format, their perceived performance in the exam, as well as students' perceptions of being selfdisciplined and quantitatively-oriented. Finally, we asked about students' perceptions of the potential usefulness of various behavioral tools as they could be applied to online learning. The full survey is included in Appendix A.

\section{RESULTS}

Even at a selective private university we find that most first-year students have not taken an online class before, or had mixed prior experiences: 87 percent had not taken an online or hybrid course before enrolling in CIS 101. Among the small number who had taken an online class previous, experiences were mixed: 60 percent agreed that the previous online course "had worked well for [them]." Overall, this suggests that first-year students' knowledge of and preferences for hybrid or online classes are still at a formative stage.

We then asked three questions regarding students' potential suitability as learners in a hybrid environment. We elicit students' self-assessment of their preferences/strengths in terms of quantitative material and academic selfdiscipline. We also ask whether the student feels that their learning style is generally conducive to a hybrid class format. Students who rate themselves as more quantitatively-oriented are more likely to rate themselves as having a learning style that is well-suited to a hybrid classroom format $(r=0.30, p<0.001)$, and students' rating of their own level of discipline is also positively correlated with the self-assessed learning style suitability $(r=0.14, p=0.026)$. However, these two groups of students (quantitatively-oriented and disciplined) are somewhat overlapping ( $r=0.16$, $p=0.014)$.

We were also interested in how students retrospectively gauged how much time they should have spent in the online content relative to the amount they did spend, and their satisfaction with their exam performance. In particular, we asked students how many minutes per day they spent in the Excel Boot Camp $(M=34.5, S D=18.1)$ relative to how much time they (retrospectively) assess they should have spent "in order to do well" ( $M=35.5, S D=18.8)$. Thus, if students see that time spent on the learning content to be important for their performance, then we would expect to see those students who were less satisfied with their performance to have a greater positive difference between the time they did spend and the amount of study they think they should have spent. Figure 1 plots precisely this relationship showing on the horizontal axis the number of minutes difference between the rated ideal time and actual time spent, and the share of students who are satisfied with their exam performance $\left(R^{2}=0.67\right)$. 


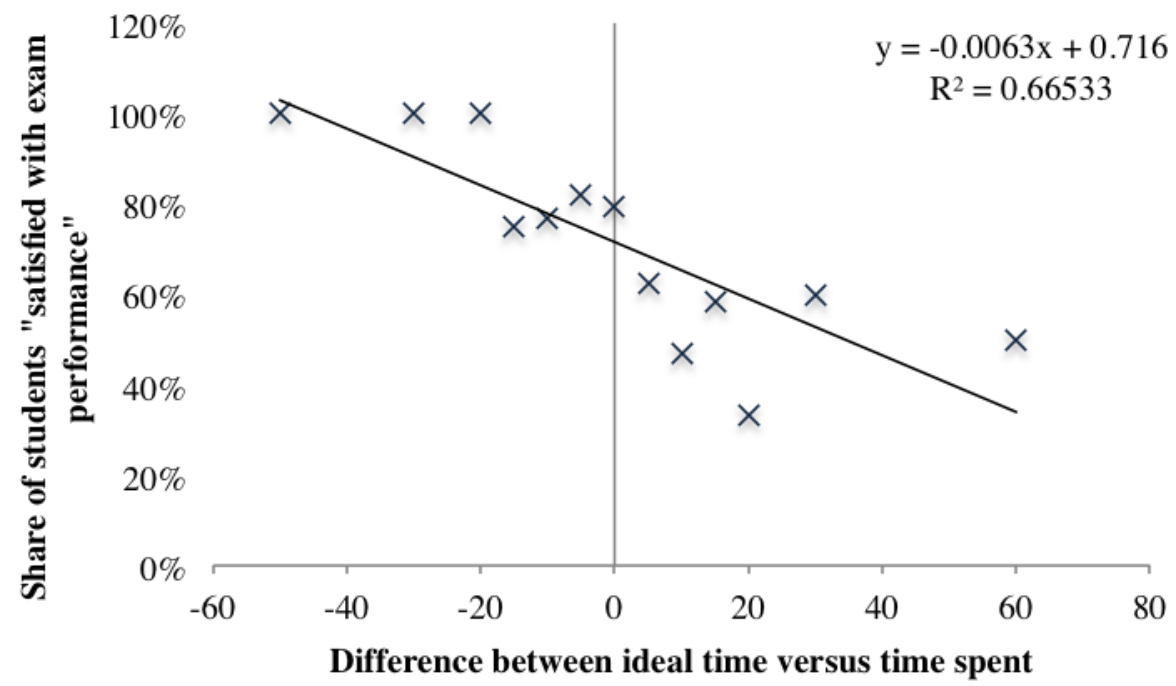

Figure 1. Perception of Whether Time Spent is Related to Performance

We also charted the relationship between actual exam performance and difference between ideal time versus time spent (not shown here). The results are comparable to the results based on satisfaction with exam performance. We understand this seemingly obvious relationship to mean that students perceive time spent to be clearly related to performance, suggesting that there potentially exists either an informational or behavioral failure that leads students to understudy during the course of the course. Thus, if time matters for performance (or, at least, students think it does) two types of interventions could possibly serve to overcome these informational or behavioral failures: information provision and commitment devices.

We then asked students in these classes about their attitudes towards these types of interventions in (hypothetical) future hybrid courses. More than half (53 percent) of students responded favorably to a question that asked whether they would like to receive occasional e-mail reminders regarding their usage of online learning materials in future courses. Interestingly, preference for regular e-mail reminders is negatively correlated with actual exam performance $(r=-0.24, p=0.03)$ and grade satisfaction $(r=-0.14, p=0.09)$, suggesting that lower performing students are more interested in information provision than higher performing students. Slightly less, but still nearly half (44 percent) of students would like to receive such e-mail reminders including additional information comparing their usage of online learning materials with that of their classmates. Preference for such social comparison e-mail reminders is not correlated with actual exam performance $(r=0.03, p=0.72)$ and grade satisfaction $(r=0.01, p=0.82)$, indicating that preference for additional information provided by social comparison is not related to student performance.

The students were then asked the following question on commitment devices:

Consider the following scenario: At the beginning of the semester, the instructor asks you to set your daily study goal for the Excel Boot Camp as the number of minutes you gave in the previous question. For every weekday that you didn't make the goal you would lose 0.5 points on the Excel exam (given a 3 week Excel Boot Camp, this means the maximum penalty would be $15 \times 0.5=7.5$ points). How likely would you be to make a commitment like this at the beginning of the semester and agree to the incentive scheme?

Mirroring the previous, approximately half of the students (41 percent) responded positively to this question, indicating some recognition on the part of students of their own behavioral failures. Openness to the commitment device is negatively correlated with actual exam performance $(r=-0.19, p=0.01)$ and grade satisfaction $(r=-0.1$, $p=0.10$ ). Interestingly, we find that responding favorably to any of the interventions (i.e. regular e-mail reminders, social comparison e-mail reminders, or commitment devices) is not correlated with SAT scores, self-rated discipline, 
or quantitative orientation (all $\operatorname{abs}(r) \mathrm{s}<0.1$, all $p \mathrm{~s}>0.16$ ) — suggesting that easily-observable factors such as these are unlikely to be related with preferences for interventions that aim to address informational or behavioral failures.

\section{CONCLUSIONS}

Students enter college with minimal exposure to online learning. Thus, they themselves are learning about learning in an online context, and are potentially receptive to new methods, tools and interventions to help them navigate this evolving environment. Students with self-perceived levels of quantitative facility and self-discipline were more likely to believe they also had learning styles that were well-suited to a hybrid-style class format, although these two groups of students were somewhat overlapping. Students definitively rate time spent with material as an important potential determinant of (satisfaction with) exam performance. Moreover, students rate two distinct types of interventions as potentially useful for overcoming informational and behavioral failures, which lead to decreased (satisfaction with) exam performance: email reminders and commitment devices. Preferences for each type of intervention could not be predicted by typical observable characteristics of students. Ongoing research investigates the relative efficacy of these types of interventions in hybrid class formats.

\section{REFERENCES}

1. Ariely, D. and Klaus Wertenbroch, "Procrastination, Deadlines, and Performance: Self-Control by Precommitment," Psychological Science, May 2002, 13 (3), 219-224.

2. Ashraf, Nava, Dean Karlan, and Wesley Yin, "Tying Odysseus to the Mast: Evi- dence From a Commitment Savings Product in the Philippines," The Quarterly Journal of Economics, May 2006, 121 (2), 635-672.

3. Bowen, William G, Higher Education in the Digital Age. Princeton, NJ: Princeton University Press, 2013.

4. Bowen, William G., Matthew M. Chingos, Kelly A. Lack, and Thomas I. Nygren, "Interactive Learning Online at Public Universities: Evidence from a Six-Campus Randomized Trial," Journal of Public Policy Analysis and Management, 2014, 33(1): 94-111.

5. Figlio, David, Mark Rush, and Lu Yin, "Is it Live or Is It Internet? Experimental Estimates of the Effects of Online Instruction on Student Learning," Journal of Labor Economics, 2013, 31(4): 763-784.

6. Giné, Xavier, Dean Karlan, and Jonathan Zinman, "Put Your Money Where Your Butt Is: A Commitment Contract for Smoking Cessation," American Economic Journal: Applied Economics, 2010, pp. $213-235$.

7. Joyce, Theodore J., Sean Crockett, David A. Jaeger, Onur Altindag, and Stephen D. O'Connell, "Does Classroom Time Matter?" Economics of Education Review, 2015, 46: 64-77.

8. Kaur, Supreet, Michael Kremer, and Sendhil Mullainathan, "Self-Control at Work," 2011.

9. Patterson, Richard W. "Can Behavioral Tools Improve Online Student Outcomes? Experimental Evidence from a Massive Open Online Course", 2014

10. Thaler, Richard H. and Shlomo Benartzi, "Save More Tomorrow: Using Behavioral Economics to Increase Employee Saving," Journal of Political Economy, 2004, 112 (S1), S164-S187.

\section{APPENDIX: SURVEY QUESTIONS}

All answers are based on a 5-point Likert scale (anchored at agree-disagree or likely-unlikely), unless otherwise noted.

1. My learning style is well-suited to the format of the Excel Boot Camp, which combines video-based tutorials with hands-on exercises.

2. I have taken an online course or online lessons before. (Yes/No)

a. If "Yes" to above question: The online course or online lessons worked well for me.

3. I am a disciplined person who does not need deadlines to get my class work done.

4. I prefer quantitative courses to writing-focused courses.

5. I would find it useful to receive occasional emails providing me with a direct comparison of my online learning materials usage with that of my classmates in future courses. 
6. I am satisfied with my performance on the Excel exam.

7. How many minutes per day would you estimate you spent in the Excel Boot Camp? (Integer response)

8. How many minutes per day should a student spend in the Excel Boot Camp to do well? (Integer response)

9. Consider the following scenario: At the beginning of the semester, the instructor asks you to set your daily study goal for the Excel Boot Camp as the number of minutes you gave in the previous question. For every weekday that you didn't make the goal you would lose 0.5 points on the Excel exam (given a 3 week Excel Boot Camp, this means the maximum penalty would be 15 x $0.5=7.5$ points). How likely would you be to make a commitment like this at the beginning of the semester and agree to the incentive scheme?

10. What is your SAT math score range? (400 or less, $401-450,451-500,501-550,551-600,601-650$, $651-700,701-750,751-800$ ) 